\title{
Sustainable Development of Society and Russian Philosophy: Educational Aspect
}

\author{
Evgenia N. Gerasimova, Aleksandr V. Usachev, Irina N. Usacheva and \\ Sergey V. Shcherbatykh
}

\author{
Bunin Yelets State University, Yelets, Russian Federation
}

\begin{abstract}
The purpose of the article is to project the general statements of the philosophical tradition and domestic psychological schools of thought on the specific situation of teaching and education, as well as to compare the historically emerging ideas of upbringing and education with modern approaches, and to trace the genetic connection and the continuity of ideas. In this context, it is possible to draw conclusions and learn lessons for the development of the modern pedagogical situation. The research results are novel and practically significant, since the main conclusion is the choice of a methodological basis for teaching natural sciences with a view to the sustainable development of society as a whole and within the framework of subject-subject relationship in particular. According to the chosen methodology, teaching information about sustainable development involves a set of interconnected methods for the purpose of their application in the educational process so to access each student individually. A special contribution of the authors is a comparative analysis of approaches to training and education, which result in the sustainable development of society.
\end{abstract}

Keywords: Man, nature, society, biosphere, co-evolution, personality-activity approach, subject-subject relationship, sustainable development, Russian philosophy, student.

\section{INTRODUCTION}

A long-term experiment, held at Bunin Yelets State University in 2015-2019 showed that neither teachers nor students have sufficient knowledge of the sustainable development of society. And they associate it with various economic, political, and military aspects in the life of society, but not with the environmental segment (Usacheva, 2019). As it is noted in one of the works: "You cannot postpone the care of the great and the eternal for the time when the opportunity for everyone to satisfy their basic needs will be achieved. Otherwise it will be too late" (Vernadsky, n.d.). Today, a significant list of sciences is engaged in the interpretation of the concept of sustainable development, both in the scientific section itself and in education.

Whereas the economic and social spheres are partially covered in the educational process, the environmental one lacks information, which must be supplemented in training courses in the natural sciences and "humanities" fields (Kirby, Jaimes, Lorenz-Reaves, \& Libarkin, 2019). The lack of ecological culture can result in divergent consequences. It is possible to get away from global environmental problems only by following the rules of sustainable development of society, proposed by the United Nations. Sustainable development of society is

*Address correspondence to this author at the Bunin Yelets State University, Yelets, Russian Federation; E-mail: Scherbatych2017@yandex.ru one of the priorities in modern reality. Environmental education inherently begins only at university, and then only in some specialties.

For instance, ecology is taught to students at Faculty of Engineering, and it is missed out for future Mathematics and the Russian language teachers. Meanwhile, environmental issues are still relevant and multipurpose. Ecological knowledge should organically constitute university students' educational competence. Therefore, the incorporation of environmental elements should be presented in all natural science disciplines so that the future teacher can integrate environmental knowledge into the corresponding subject area, and be able to develop children's ecological culture.

Environmental issues cannot be abstracted from the state of nature throughout the world. An integrated approach should be characterized by the fact that the natural and human sciences should jointly solve the issues of this topic, based on the fact that it carries a worldview load and can contribute to a common understanding, which will lead to a change in attitudes towards basic concepts. Funds are needed to popularize the ideas of ecology and sustainable development, so their presence in educational programs becomes necessary. This wording, adopted as the basis in Rio Declaration on Environment and Development in 1992, has become the most significant topic in all developed countries, including Russia. In this context, sustainable development is not quantitative, but qualitative thinking, which is created by many factors of a natural, technogenic, and anthropogenic nature. 
Sustainability today is the main circumstance that allows planning person's activities, look far into the future and create images of how a person will live after a certain period of time. In order to make such thinking possible, interdisciplinary communications in their totality are necessary, which would allow creating the picture of the present and the future as fully as possible. It should take into account the lessons of the past, which led mankind to the need for a new type of thinking, which includes increased responsibility to current and future generations in the sense what modern civilization can leave behind the future levels of civilization.

The unbridled race for profit and prosperity today already looks like an old-fashioned task, which is corrected by the fact that everything on Earth can completely disappear under certain adverse conditions, which means that planning elementary actions without taking into account the sustainable development features can become completely meaningless and unnecessary. The idea of industrial production growth today is inseparable from the growth of human consciousness. Sustainable development is not just a declared principle, but a methodology of scientific research and a universal goal, towards which all the efforts of mankind are directed creating signs of their own well-being.

That is why the study made an attempt at empirical research, which is based on real practice of teaching ecology and conveying the meaning of sustainable development to school and student audiences. The research context consists of discourses formed by works on Russian cosmism, Russian philosophy, which raise the question of a person who is united by his destiny with all of humanity. The specified context is relevant for posing questions, which will be addressed later in this article.

A steady increase in needs must be accompanied by the restoration of a favorable environment for both current generations and future ones. These actions should be accompanied by improvement of environmental legislation, which will exclude production and consumption development models that impede sustainable development. It is these circumstances that are capable of influencing today the politics of states and their interaction in the system of the whole world. Many current problems are evident at a planetary scale, which should be corrected by joint initiatives that are consistent with the national interests of different countries, and especially those that are in a high risk area to harm the environment. A special role is played by Rio Declaration on Environment and Development (1992), which contains Agenda 21, the essence of which should be rendered in the course of environmental education. The younger generation should be fully aware that the responsibility to preserve the environment will soon be borne by them, and they will have to take care that the forests, fields and rivers are preserved in such a way that the environment does not experience destruction stress.

\section{LITERATURE REVIEW}

At each enterprise, there should be in-process monitoring, which is able to provide a background for adjusting production and functioning conditions, the purpose of which is a careful attitude to nature, as well as forming the foundation for the reproduction of natural factors in the form they can further exist (Boekhout, 2009). It is especially important to cultivate the noospheric thinking because it is interdisciplinary, which is not only systematic, but also the integrity of the vision of what you need to pay special attention to. Noospheric thinking is an integral part of ecological thinking, which assumes that all manifestations of the natural world are interconnected and can receive an interpretation of the universal connection of the phenomena of the surrounding reality. The noosphere is the reality of intelligent reality, which is of decisive importance in all manifestations of the relationship between a human being and nature. In this sense, noospheric thinking unites all essential and existing ideas that lead to a change in attitude towards the Earth as a common home.

It is necessary to identify vulnerabilities that require increased attention and special participation of a person, based on the achievements and conclusions of ecology (Braakman, Follows, \& Chisholm, 2017). In this approach, one can also note a significant share of pragmatism in nature consideration (The Problem of $A$ human being in the Western Philosophy: Translations, 1988). Preserving natural habitats today, we can say that in the near future, stability in natural conditions will allow acting optimally while solving various life-related and industrial issues (Rashid, 2019). It is no coincidence that ecology as a discipline arose in the era of industrial capitalism and rapid industrial growth (Heidegger, 1993).

This suggests that the coexistence of industrial assets and the environment becomes the first important task to fulfill all conditions for a modern 
person (Rasheed et al., 2019). The idea of ecological perception of reality is associated with the idea of sustainable development of society, in which the share of collisions and catastrophes of technogenic and anthropogenic nature will become minimal (Jovanov, 2019). It is no coincidence that the sustainable development of society had the status of an obstacle to the expansion of production. Only in the 20th century did mankind realize that this is currently the only solution that can harmonize human life and nature (Moiseyev, 2016).

There should be mutual understanding based on shared spiritual and cultural values. Using the ideas of Russian philosophy on the process of joint comprehension of circumstances that aggravate the situation, the concept of "unitotality" is most suitable (Moiseyev, 2016). This involves "the positive unitotality of life, knowledge, and creativity", about which Soloviev (1990) wrote. It includes a feature of the inalienable unity of nature and space. In a more particular wording, one can say: what happens to a person happens throughout the cosmos, and what happens throughout the cosmos happens to every person (Boekhout, 2009).

For example, the problem of rational use of natural resources considers the most important point to be the natural assimilation of some production wastes and the unacceptability of others. In this sense, every person who consists in the substance exchange between nature and society is an active participant in this process (Braakman, 2019). The effectiveness of the process that will be activated by nature for natural processing depends on his spirituality and level of culture, or he will become an active participant in the environmental pollution. The concept of unitotality explains this in the best way. In the educational process, the question concerns not only the students' awareness of what is right to do in this regard and what is not (Vernadsky, n.d.).

This allows one to see in another subject an active participant in the process of a balanced attitude to nature (Leroy, 1999). Second, the subject-subject relationship emphasizes the potential for sustainable development of society, since there is a quality of conventionality, that is, the participation of everyone's opinions in the overall process of stabilizing relations with nature and society as a whole. Third, such a construction allows seeing the subjective principle not only in another person, but also in oneself, which becomes the foundation of self-consciousness. It suggests that a person, according to his inner culture and inner spirituality, skillfully regulates his attitude to nature and society and assumes the same skill in another person. This creates the basis for the priority of agency rather than narrow abstract subjectivity. Fourth, the subject-subject construction forms the basis of a deeper understanding among active participants in creating the foundations of sustainable development of society.

The article states that it is impossible to develop an idea of the sustainable development of a society based on the increasing level of environmental knowledge without integration work. Therefore, it is necessary to scale up educational material on environmental topics at the university within the allotted hours. It is no secret that pupils and students represent a very significant segment, if not the main one, in understanding the realization of social dynamics, with their own worldview, emerging background, and habits (Kobylyansky, 2010). In this respect, the development of environmental thinking is a necessary component of both the educational process and the active life position of young people. This position should integrate the elements of ecological culture that can be taken over in the educational process both in a secondary school, a specialized secondary educational institution, and a university.

\section{METHODOLOGY}

Russia has developed a set of topics that most closely meets the methodology for solving this problem. The theoretical issues of studying and teaching the topic of sustainable development of society are becoming the most relevant today and have an ideological character. Numerous literature is devoted to this issue. The methodology is compiled applying historical-genetic that allow studying the history of the issue of the formation of the concept of sustainable development and its application in pedagogical practice. To verify the methods of teaching the concept of sustainable development, it is necessary to compare different approaches to what place ecology and other worldview disciplines should occupy in the educational process. The research methodology covers the following aspects:

1. Poisoning of the environment - atmosphere, water, deforestation and pollution of the earth's surface, rapidly growing with increasing population and consumption (Rasheed, Bilal, Nabeel, Adeel, \& Iqbal, 2019); 
2. Resource depletion - fuel, etc. (Lieber, NimmoSmith, Waggitt, \& Kregting, 2019);

3. The growing scale of military conflicts; there were two global wars in the previous century. The causes of conflicts are territorial claims, religious and ideological disagreements, national and social hostility, leaders' ambitions; in the long term, the aggravation of the struggle for resources and confrontation over environmental matters (Braakman, 2019);

4. Continuation of technological developments to improve nuclear (apparently, both chemical and biological) weapons and create new weapons of mass destruction based on nanotechnology, biotechnology, robotics, and other fields of science. Improving weapons delivery systems. Militarization in near space (Tofler, 2005);

5. The threat of global economic crises that exceed all previous ones and are capable of plunging mankind into chaos with unpredictable consequences (Kirby et al., 2019);

6. Natural disasters are not so rare: geophysical, planetary phenomena - earthquakes, volcanic eruptions, climate change; space phenomena dangerous radiation flashes - from the Sun and distant stars. Life on the planet (of part of the population) may also be threatened by rarer catastrophes - large asteroids fall, fluctuations in the level of the oceans, and a change in the Earth's magnetic field (Jovanov, 2019).

As for the heritage that comprehends this state of affairs, first of all, we are talking about the philosophy of Russian cosmism, within the framework of which the concepts of "noosphere", "unitotality", "co-evolution" appeared and developed. We should not forget that the center of all educational efforts is the child, or the student. Therefore, the anthropological component should be at the forefront. Ecology is an interdisciplinary branch of science (Kobylyansky, 2010), which should take into account the achievements of all sciences and rely on the main discoveries of its time so that its conclusions can be extended to other scientific fields to achieve mutual understanding and the effect of cooperation in this direction (Zimmermann, \& Seiler, 2019).

It is important to understand that theoretical development must be comprehensive and take into account the impact of many kinds of human activity on the wildlife in order to take it into account in further activity planning. One condition is important here: all aspects of the activity should be adjusted according to the conclusions that are made in the course of environmental studies (Kirby et al., 2019). In this regard, ecology should take a leading place in studies of nature and the environment so that further steps are made based on the conservation of nature and its main qualities (Kates, 2011). Atmospheric air conservation, waste disposal rules, gas pollution ratios - all this becomes essential constituent parts, which should make a single integral picture of human impact on nature and the environment (Tofler, 2005).

The method of analysis and synthesis allows approaching the subject-object dichotomy from different perspectives. First, we are talking about considering this pair (analysis and synthesis) of categories in the educational process, and the rationale for their constructiveness related to education and training. The historical-genetic method deals with the research subject from its development over time. In 1996, the President of the Russian Federation adopted a decree on the transition of our country to the path of sustainable development. This was the beginning of a philosophical and pedagogical development, which implied the inclusion of sustainable development topics in the educational process, for example, in courses in the natural and human sciences. Ecology has taken on the form of an integrated discipline, within which the concept of sustainable development was most widely represented.

Ecology has become the most widespread science, (Kobylyansky, 2010) along the paths of which the necessary balance is sought between man, society, and nature. In this context, an ecologically oriented educational process aims to harmonize such spheres as a society, nature, and a human being. Educational aspects are evenly distributed between environmental management, environmental protection, and environmental literacy of citizens of the country. Numerous discussions have revealed sharp contradictions between the technological development of production and the tasks that make up the sense of sustainable development (Moor, Van Haitsma, Curito \& Saperstain, 2003). An exceptionally technogenic section of the development of society leads to ecological collapse. But a change in attitude towards technology does not prevent this trend. They should be primarily spiritual in nature and create a different formulation of the issue on the use of natural resources and the technologization of all life processes (Braakman et al., 2017). 
Priorities should be made taking into account the steady development of technical civilization, and only spiritual development can take this pace fully into account. Spirituality in this case is not an abstraction, especially taking into consideration the Russian philosophical heritage related to such concepts as the unitotality and the cosmic worldview. Synthesis and harmony in a system such as man-nature-society allows thinking that the spiritual scope of the global trend towards technological improvement can be productive and constructive. Another important category should be considered in the concept of spirituality. The point at issue is culture. In its literal sense, it means cultivation, education, and respect. Culture contains all the necessary skills and knowledge of communication with nature and society both in the national and universal sense.

Based on Elets State University, questions were held on environmental problems in their native land, Russia and the world as a whole. As a tool, we used questionnaires that were developed by scientists from Elets State University. The questionnaires included from 5 to 15 problem questions. The sample was made up of representatives of the university itself and educational institutions of Yelets.

Culture and spirituality are the closest concepts. This means that the study of culture leads to an increase in the level of spirituality, and a change in the situation with spirituality will lead to positive changes in the culture of each person. Culture is not a mechanical set of values and artifacts, but a system of views and knowledge of a person in the process of cognition of nature and society (Kobylyansky, 2010). Therefore, its development, increasing its level in every person and society as a whole, should be systemic. The backbone factor is the joint activity of people who comprehend the problems that all people face equally (Martínez, Estrada, \& Prada, 2019).

\section{RESULTS}

Since the problem of sustainable development has a systemic nature, comprehensive knowledge is needed, which dialectically transforms into culture and affects spirituality. Information about these processes stated in the subject-subject framework should emphasize that both the teacher and the student are not separated from communication with nature to the same extent, but are participants in the substance exchange with the environment. The rules and knowledge apply to them equally, and therefore the learning process should be mutually dependent.
In 2019, a study was conducted by the Yelets State University among students of the city of Yelets on a special sample of 108 people. It was decided to select the 1st year students of this university in order to understand what knowledge of ecology and sustainable development of society the students came to the university with. A survey was conducted. The questionnaire included 1 question:

1. Does technological progress have a negative impact on the environment?

The question was intended to assess the level of students' knowledge, their involvement in environmental issues, as well as reflection on their own behavior in matters of the ecological state of the environment. The results of the survey were processed by the methods of mathematical statistics. Statistical processing of the results was carried out using the statistical package "STATISTICA for Windows. Release 5.0". For statistical processing, the results of a questionnaire survey of representatives of different study groups were selected at random using a computer. The analysis was carried out using several criteria: (Wilcoxon test), sign criteria (Sign test), and Student's criterion (T-test).

The results include the following data: $27 \%$ of respondents are convinced that the negative impact of technological progress on the environment is clearly exaggerated. At the same time, $73 \%$ of respondents strongly disagree with the first group. Indeed, according to their answers, resource depletion, environmental pollution, violation of the ecological balance and the totality of elements of technological progress negatively affect living conditions. A large group of respondents expressed their willingness to take part in environmentally friendly actions: the students proposed their plans for cleaning up places of residence and leisure.

With the support of the Russian Academy of Sciences in 2020 within the framework of the conference "Moiseyev N.N. about Russia in the XXI century: global challenges, risks and solutions" (Moiseyev readings, 2020) on the basis of Yelets State University, a discussion was organized on various issues of environmental education. The discussion was attended by officials, teachers, students, stakeholders, who expanded the range of issues for discussion. In particular, the following questions were raised:

1. What is everyone doing to improve the environmental situation in their city? 
2. What is the level of environmental protection of your hometown (Yelets, Russia)?

3. What can students do to make the environmental situation more favorable?

4. How do you understand the principle of sustainable development of society?

5. Is it important to include the topic of sustainable development of society in educational programs?

During the discussion, opinions were expressed that the ecological situation in the town of Yelets is quite favorable, but far from perfect. The educational process can provide basic constructions for the ecology of the city and the region to be organized at a scientific and practical level and combined with the concept of sustainable development of society (Moiseyev Readings, 2020).

The practice of organizing and implementing projects of Olympiad tasks in ecology among students and schoolchildren in Russia is based on numerous experiments (Zakharov, Kolesova, 2014), which provide information in order to draw a number of conclusions. These experiments show that the idea of sustainable development is perceived very organically by students and does not require additional comments and can serve as a reference signal for the arrangement of educational and scientific activities. Experimental data of various developments in ecology among students and schoolchildren, containing the results of studies of different levels, conducted over the past five years, show:

- $\quad$ An in-depth understanding of the dependence of natural conditions on the types of human activities:

- Ability and skills to apply the principle of sustainable development in theory and practice;

- $\quad$ Confidence in the need to apply environmental issues in research at various levels;

- Interest in the development of environmental issues in solving certain scientific problems (Guseva, 2020).

The idea of the simultaneous development of society and nature is reflected in training programs and the implementation of plans for the future. This is of particular importance during the period of economic reform in Russia, which is embarking on the path of nature conservation and raises the question of industrial environmental control at different levels. In educational institutions, the topic of ecology becomes a subject for study, as well as an olympiad movement, during which students and schoolchildren can offer their projects on ecology. For the concerned members of society, the truth of the 20th century is obvious: society can no longer develop in such a way as not to take into account various aspects of environmental protection (Rasheed, 2019). The implementation of this thought should begin as early as possible and affect the maximum number of generations in order for them to enter the active phase of their life-time possessing this idea. One cannot ignore the fact that it is impossible to develop the foundations of environmental protection without developing the economy. There is an integration of effort, according to which the economy and the environment must go together. Principles such as the human right to a healthy life in harmony with nature, environmental protection as an integral part of the development process, become not abstract, but specific, becoming explicit in various scientific and educational projects.

In addition to the natural sciences, the humanities are connected to the research of this topic, which thinks at the level of ideas that can be implemented in curricula in biology, philosophy, pedagogy, psychology, and other subjects. The equally directed aspiration of philosophy, pedagogy, and psychology must be generalized regarding a person considering such entities as the student and the child. As Berdyaev (2003) states in one of his works, "throwing out knowledge from objective reality is the fatal fruit of rationalistic enlightenment, which has not been completely eliminated and has not been overcome".

The existence of the triad of human-society-nature is the objective goal of the activity of educating the student and the child. This process seems multilevel and complex. Philosophers and scientists worked on this topic, actively defending the human right to be in the unity of the triad man-nature-society. The scientists and philosophers such as V.I. Vernadsky, N.A. Berdyaev, V.S. Soloviev, N.F. Fedorov, P.A. Florensky and others are among them. Thanks to their work, today it is possible to fully explore the holistic understanding of man, whose main feature is the priority of spirituality and the absence of formalism in a social concept.

As the most noticeable theoretical developments of the topic of man, one can single out such as a 
universalist one, which considers a human being to be part of the universe, on which A.N. Herzen and V.I. Vernadsky worked most actively. One cannot ignore the socio-pragmatic theory, which analyzes the essence of a human being as a set of social relations. The most active research is related to the spiritual and religious interpretation of the essence of man, which N.A. Berdyaev, P.A. Florensky, and I.A. llyin dealt with.

The concept of subject is the key one in bringing about the issue about a human being in the universal framework. The subject is part of the general dichotomy of subject and object. The notion of the subject is thought of as an active organizing principle, possessing self-awareness, projective activity, and a certain goal-setting in the process of activity. As Heidegger (1993) mentions in one of his works, "...all awareness of things in existence as a whole is traced to the self-consciousness of the human subject as the unshakable foundation of all reliability". It is significant that the concept of activity was introduced at the beginning of the 18th century by I. Kant, and already in the 19th century, activity became a philosophical category thanks to the works of G.W.F. Hegel, K. Marx, and L. Feuerbach, who widely used the concept of subject.

The concept of subject includes several levels: organization of activity, the formation of selfawareness, the perception of an objective situation, as well as the status of the subject of influence. A comprehensive perception of information about the world with a view to correlating it with the reality of nature and society in their particular balance and unity cannot be without subjective reflection. In this context, it is important that in the process of formation of sustainable development of society, the educational process aimed at the formation of subjectivity in the child with his intuitive experience also takes its place (Boekhout, 2009). The semantic sphere of training and education, in this case, is focused on the student himself in such a way so that his participation in the triad of man-nature-society is aimed at the formation of subjective qualities (Rasheed et al., 2019).

The latter emphasizes an individual way of perceiving information in a certain situation. In turn, agency manifests and emphasizes the ability of a person to organize his activities in such a way that his personal position and unique mode of activity is visible (Jovanov, 2019). This suggests that the student is active in creating programs that can act as parts and elements of a common focus on sustainable development of society. A special role in this process is played by the personality-activity approach, which leaves aside the factor of adaptation to external conditions and puts the activity aspect of training at the forefront. In the process of cognition and activity, social experience is acquired.

Sustainable development of society can be understood as a static and dynamic phenomenon. In a static sense, we are talking about theoretically defined elements, which should make up the set of humanitarian and technical components, totaling in the stability of man, nature, and society. Most often, theoretical developments can be defined just static. Dynamic understanding emphasizes the term of 'development' and assumes a mobile correlation of the developing parts that make up stability (Collado-Ruano, 2019). It is here that an urgent need arises for the anthropological aspect. In this context, the personal agency becomes an unrivaled value, to which special attention should be paid. There is a dialectic relationship between the static and dynamic explanation. If there is no theory, then the practice of organizing sustainable development will be implicit.

The guess activity is a very dangerous development, having no prospects. Static understanding, which is not a prerequisite for moving towards a sustainable development of society, will also be wasted. Therefore, theory and practice must coexist organically. A human being cannot refuse his social existence, since he is woven from social relations, and he is their subject.

In this sense, the concept of co-evolution, which provides for reciprocal changes in nature to changes in society, is fundamental. An environmental education program should take this point into account so that each subject of social development possesses sufficient knowledge and is able to respond to complex and simple situations simultaneously with changes, with the goal of sustainable development of existing components.

The program should go from simple to complex, that is, with a constant change in the preponderance from static to dynamic elements and should go to the active phase of the person's subjective activity. In this case, the sustainable development of society acquires the most important condition for its existence: the mutual communication of subjects with one goal, united by one task. In Russian philosophy, the moment of revolutionary changes in society was experienced with particular acuteness and sensitivity. 
The eternal question is: to what extent revolutionary transient changes could pass more thoughtfully in a different logic of events? In fact, revolutions did not bring freedom to subjects and nature, leaving them in the status of material for consumption. This panEuropean trend captured the Russian world for a while, which correlated with the phenomenon of Russian philosophy.

Therefore, in philosophical works, Russian philosophers sought to comprehend the saturation of changes with events in their cosmic integrity (Popper, 2004). Concepts such as the noosphere, evolution, coevolution, and economy, have become at the forefront of their thoughts. Today it is becoming an integral part of the teaching modules, which contain knowledge of ecology, in the exact sense of the word, if we understand ecology as the homebuilding and the arrangement of our own living space.

\section{DISCUSSION}

Consumption of energy resources, energy-intensive industries that make nature a commodity, as well as global competition in these matters, are forcing us to become more active in improving environmental knowledge and skills (Abramyan, 2012). It is a question of changing attitudes towards these issues at the level of modifying the value system and placing emphasis and priorities (Collado-Ruano, 2019). There is a need to go deeper into the study of the heritage of Russian cosmism, personalism, existentialism in order to integrate this knowledge into educational programs that will allow the development of co-evolution factors (Vernadsky, 2019).

Cosmism is a universal doctrine that combines philosophical and natural science issues related to solving the problems of sustainable development of society in the context of environmental problems. He promotes the idea that the forces of humanity can be combined not only theoretically but also practically. In particular, environmental education, which has an ideological character, can be a practical step (Kobylyansky, 2010). It is also important to highlight the subjective and objective aspects of these processes (Kates, 2011). If the economic pace of consumption and the global market constitute the objective aspect, then the environmental component of education, with all the skills to take care of and competent attitude to nature, is the subjective side, which has the qualities of a personal creative balanced approach with elements of individual's personal freedom (Rasheed, 2019).
The thesis that any human action impacts all nature and any natural phenomenon has a response in a person takes on special significance (Boekhout, 2009). Self-control of individual's own activities should result in a positive outcome of environmental education ( Moiseyev, 2016). In the status of a subject, a person will not be considered as an impersonal object of the world arrangement (The Problem of a Human Being in the Western Philosophy: Translations, 1988). A person with universal consciousness will be perceived as the concept of man. The concept of self-organization, in turn, is an essential component of the methodology to study co-evolution. It assumes the existence of independent systems in the interpretation of the biosphere and man.

This idea is presented in works by Moiseyev (2016): "...having entered the era when the power of civilization is such that its future depends on the depth of a possible dialogue between a human being and Nature, into which we are gradually starting to get involved, people, as it seems to me, should be aware that today we should talk not so much about the ideals of the distant future, but about much more "earthly" things: we must accept the inevitable - the forms of social existence cannot but be limited to a certain framework". According to his considerations, there are its own laws in nature, which, as a self-developing system, will respond to any impact. Consequently, the sustainable development of society is a necessary condition for coevolution (Jovanov, 2019). It contains a certain understanding of the personality-activity approach, and within its framework, a person is supposed to be an active being, a subject in the process of development.

A human being is able to systematically and harmoniously change the world around him and, at the same time, can change himself and his understanding of the world. This also means a special approach, which is called the "activity component", and it has diverse prerequisites for the development. It is especially important to understand this when it comes to education. It is significant to note the subject-subject relationship of the teacher and student in order to emphasize the student's activity. Subject-subject relationship has several levels. First, the necessary level of culture at which the fellow human being will act not only as an object of influence, but also as a subject of joint action.

\section{CONCLUSION}

This research has a perspective in the educational process. It can be implemented in the improvement of 
natural science and humanities courses, where environmental issues can be presented in an expanded form. Also, problems of ecology and sustainable development have a philosophical perspective in topics such as philosophy of ecology, philosophy of sustainable development, in ongoing research on Russian cosmism. Comprehensive research at the intersection of such sciences as philosophy, ecology, psychology, and pedagogy is of the greatest importance. In the meantime, the scale of the topic is faced with a reduction in hours in schools and universities, which adversely affects the coverage of this issue. The problem of this study is that data are taken for one region, but there is no broader coverage of the issue of sustainable development of society in other regions of Russia and the world.

The concept of sustainable development includes economic, social, and environmental components. The current situation in domestic education is such that the ecology course has been excluded from the federal educational school standards since 2001. In Russia, in academic research, this topic can be called a priority, since the Moiseyev Readings are held on a regular basis, which summarize the annual work on this topic. Therefore, teachers have to provide environmental knowledge in certain topics within other disciplines. The inculcation of ecological culture is further complicated by these circumstances (Kobylyansky, 2010). These documents were adopted in Russia in order to restructure the educational process in order to convey the goals of sustainable development based on the ideas of Russian philosophical thought to students in Russia.

The conceptual value of the proposed approach consists in a constructive search for new foundations for the transfer of knowledge on sustainable development of society, which imply the following provisions:

1. The issues of environmental education and upbringing are now becoming very relevant (Moiseyev, 2016);

2. In environmental issues, Russian philosophy and its ideas, concerning the possible negative consequences of technical progress, acquire constructive and methodological significance;

3. The transition from abstract subjectivity to substantive subjectivity is possible provided that the Russian philosophical tradition and modern research in this area are studied;
4. Noospheric thinking, the activity of the mind to reconcile contradictions, remains the main task towards which students and all active members of the society should be oriented;

5. Fostering respect for natural environment and reasonable behavior in social relations is the main task of education.

6. In the educational system of Russia there are strong opportunities to include the topic of sustainable development and ecology in the educational process on a regular basis, both in the cycle of natural science disciplines and the humanities. This study shows the effectiveness of the results of this approach to business. The topic of sustainable development has already become an educational one and is bearing fruit in education. Studies show that a significant number of respondents from among students (up to $70 \%$ ) believe that technological progress brings negative consequences for nature.

\section{REFERENCES}

Abramyan E. A. (2012). Rio Sustainable Development Conferences (1992-2012). http://globosfera.info/2012/09/23/konferentsiirio-po-ustoychivomu-razvitiyu-1992-2012/

Berdyaeva N. A. (2003). The Experience of Paradoxical Ethics. Kharkiv: Folio.

Bettencourt L. M. A., \& Kaur, J. (2011). The evolution and structure of sustainability science. PNAS, 108(49), 19449-50. Corpus ID: 197410285 https://doi.org/10.1073/pnas.1102712108

Boekhout, B. (2009). Concepts of Sustainability. Uppsala, 157(8).

Braakman, R. (2019). Evolution of cellular metabolism and the rise of a globally productive biosphere. Free Radical Biology and Medicine, 140, 172-187. https://doi.org/10.1016/j.freeradbiomed.2019.05.004

Braakman, R., Follows, M. J., \& Chisholm, S. W. (2017). Metabolic evolution and the self-organization of ecosystems Proceedings of the National Academy of Sciences of the United States of America, 114(15), E3091-E3100. https://doi.org/10.1073/pnas.1619573114

Collado-Ruano, J. (2019). Philosophical reflections on Education for Sustainable Development: A complex, transdisciplinary, and biomimetic approach. Foro de Educacion, 17(26), 135-152. https://doi.org/10.14516/fde.575

Guseva, M. V., Blokhin, L. V., \& Kubareva, M. V. (2020). The value of environmental education in the system of environmental protection. From environmental education to the ecology of the future. VI All-Russian scientific-practical conference on environmental education (Moscow, October 30 - November 1, 2019): Collection of materials and reports. Scientific publication. Edited by V. A. Grachev. Moscow: Foundation named after V. I. Vernadsky. ISBN 978-5-9907508-9-0

Heidegger, M. (1993). Being and Time. Articles and speeches. Moscow: Respublika.

Jovanov, E. (2019). Wearables meet loT: Synergistic personal area networks (SPANs). Sensors (Switzerland), 19(19), 4295. https://doi.org/10.3390/s19194295 
Kates, R. W. (2011). What kind of science is sustainability science? PNAS, 108(49). https://doi.org/10.1073/pnas.1116097108

Kirby, C. K., Jaimes, P., Lorenz-Reaves, A. R., Libarkin, J. C. (2019). Development of a measure to evaluate competence perceptions of natural and social science. PLOS ONE, 14(1), e0209311. https://doi.org/10.1371/journal.pone.0209311

Kobylyansky, V. A. (2010). Philosophy of Ecology. Moscow: Academic project.

Leroy, P. (1999). Social and Political Sciences of the Environment. Three Decades of Research in the Netherland. Utrecht: Int. Books.

Lieber, L., Nimmo-Smith, W. A. M., Waggitt, J. J., \& Kregting, L. (2019). Localized anthropogenic wake generates a predictable foraging hotspot for top predators. Communications Biology, 2(1), 123. https://doi.org/10.1038/s42003-019-0364-z

Martínez, L. M., Estrada, D., \& Prada, S. I. (2019). Mental health, interpersonal trust and subjective well-being in a high violence context. SSM - Population Health, 8, 100423. https://doi.org/10.1016/j.ssmph.2019.100423

Moiseyev, N. N. (2016). Works on education. http://partnerunitwin.net/wp-content/uploads/2016/08/Моисеев-Н.Н.-обобразовании.pdf

Moor, K. D., Van Haitsma, K., Curito, K., \& Saperstain, A. (2003). A pragmatic environmental psychology: A metatheoretical inquiry into the work of $\mathrm{M}$. Powell Lawton. Journal of environmental psychology, 23(4), 471 - 482. https://doi.org/10.1016/S0272-4944(02)00116-0

N. A. (1988). The Problem of a Human Being in the Western Philosophy. Moscow: Progress.

N. A. (2020). Moiseyev Readings: "Moiseyev N.N. about Russia in the XXI century: global challenges, risks and solutions" (March 2-6, 2020), Moscow. Collection of reports XXVIII Moiseyev Readings (MCh-20). https://buran-sas.ru/sbornikmch-20/
Popper, K. R. (2004). Assumptions and rebutments: The advance of scientific knowledge. Moscow: AST Publishers; NPP Ermak ZAO.

Rasheed, T., Bilal, M., Nabeel, F., Adeel, M., \& Iqbal, H. M. N. (2019). Environmentally-related contaminants of high concern: Potential sources and analytical modalities for detection, quantification, and treatment. Environment International, 122, 52-66. https://doi.org/10.1016/j.envint.2018.11.038

Rashid, L. (2019). Entrepreneurship education and sustainable development goals: A literature review and a closer look at fragile states and technology-enabled approaches. Sustainability (Switzerland), 11(19), 5343 https://doi.org/10.3390/su11195343

Soloviev, V. S. (1990). Works in 2 Volumes. Moscow: Mysl.

Tofler, E. (2005). War and anti-war: What is war and how to deal with it? How to survive at the dawn of the 21st century? Moscow: AST Publishers: Transitkniga.

Usacheva, I. N. (2019). Problems of the formation of ecological culture in education. Modern science-intensive technologies 5, 388-394. https://doi.org/10.17513/snt.37891

Vernadsky, V. I. (2019). Citations. https://citaty.info/man/vladimirivanovich-vernadskii

Zakharov, V. M., \& Kolesova, E. V. (2014). The role of professional communications in the development of environmental education and enlightenment. Environmental education for sustainable development: a step into the future. Proceedings of the conference on June 26-27, 2014. Moscow: MNEPU Publishing House. ISBN 978-5-7383-0389-0

Zimmermann, B., Seiler, S. (2019). The relationship between educational pathways and occupational outcomes at the intersection of gender and social origin. Social Inclusion, 7(3), 79-94.

https://doi.org/10.17645/si.v7i3.2035

Received on 29-11-2020

DOI: https://doi.org/10.6000/1929-4409.2021.10.13

(C) 2021 Gerasimova et al.; Licensee Lifescience Global.

This is an open access article licensed under the terms of the Creative Commons Attribution Non-Commercial License (http://creativecommons.org/licenses/by-nc/3.0/) which permits unrestricted, non-commercial use, distribution and reproduction in any medium, provided the work is properly cited. 